\title{
Decadal stability in top predator habitat preferences in the Bay of Biscay
}

\author{
Lambert $\mathrm{C}^{1,{ }^{*}}$, Authier $\mathrm{M}^{2}$, Doray Mathieu ${ }^{3}$, Doremus $\mathrm{G}^{2}$, Spitz $\mathrm{J}^{2}$, Ridoux $\mathrm{V}^{1,2}$ \\ ${ }^{1}$ Centre d'Etude Biologique de Chizé, UMR 7372 CNRS - Université de La Rochelle, 17000 La \\ ${ }^{2}$ Observatoire PELAGIS, UMS 3462 CNRS - Université de La Rochelle, 17000 La Rochelle, France \\ ${ }^{3}$ Ifremer, EMH, rue de l'île d'Yeu, B.P. 21105, 44311 Nantes Cedex 03, France \\ * Corresponding author : C. Lambert, email address : charlotte.lambert@univ-Ir.fr
}

Rochelle, France

\begin{abstract}
:
Most oceanographic systems, especially shelf ecosystems, are characterised by interannual variability in the timing, extent and intensity of their seasonal patterns. Such interannual variations have important consequences on top predator habitat preferences. Capitalising on oceanographic surveys performed every spring since 2004 in the Bay of Biscay (BoB), this study explored interannual variations in habitat preferences exhibited by five mobile top predator species: bottlenose and common dolphins, auks, fulmars and northern gannets. We expected to find species with similar habitat preferences every year or species exhibiting important variability in their habitat preferences. First, we identified with a Principal Component Analysis (PCA) three different habitats of varying extent depending on year: river plumes, central shelf waters and shelf edge. Second, the Principal Components were used to explore the habitat preferences of predators through Generalized Additive Models. We fitted two kinds of models, using and not using the year as an interaction term, to test whether habitat preferences changed across years. Our results showed a range of habitat strategies based on the specificity and stability of species preferences. Species exhibiting narrower habitat preferences also exhibited stronger stability in their preferences among years while the species with wider habitat preferences exhibited higher variability among years. The target habitats differed across studied species, with bottlenose dolphins targeting the shelf edge exclusively, auks preferring river plumes, fulmars exhibiting a gradual preference from the shelf edge to river plumes and gannets being present in any of the three habitats. In contrast, the habitat preferences of common dolphins, the most sighted cetacean species in the BoB, could not be reliably inferred.
\end{abstract}




\section{Highlights}

- Concurrent sampling of predators and habitat unveiled their relationships in time. PCA on environmental variables identified 3 main habitats used by predators. Predators exhibited various habitat preferences specificity and stability in time. Narrower habitat preferences paired with stronger stability among years. Wider habitat preferences paired with higher variability among years.

Keywords: Habitat preference, Temporal variability, Cetaceans, Seabirds, North Atlantic, Bay of Biscay 


\section{Introduction}

2 The marine environment, and especially pelagic ecosystems, is highly dynamic due to complex interactions between physical and biological processes. The resulting heterogeneous and dynamic structures vary in timing, extent and intensity at many scales (Barry \& Dayton, 1991; Longhurst, 2007). Over continental shelves, for example, annual variations in river discharge determine nutrient inputs (Simpson, 1997), while the localisation and intensity of eddies associated with either currents or slope can fluctuate from year to year (Longhurst, 2007).

Heterogeneity is a challenge for species, as they must make accommodation for spatio-temporal variability in resources to ensure survival. Many species have evolved to target discrete and predictable oceanographic features (Ballance et al., 2006; Weimerskirch, 2007). This is the case of homeotherm top predators (cetaceans, seabirds and pinnipeds) which are associated with specific coarse and meso-scale habitats such as eddies and filaments (Tew-Kai et al., 2009; Cotté et al., 2011), tidal or river plume fronts (Jahncke et al., 2005; Skov \& Thomsen, 2008) or shelf edges (Cañadas et al., 2002; Azzelino et al., 2008; Guilford et al., 2012). In addition to their sensory skills, most of these predators can rely on memories or social learning to locate these favourable habitats (Davoren et al., 2003) and they are highly dependent on spatial and temporal repetitiveness to find them.

Homeotherm top predator species exhibit a wide range of biological traits (Gaston, 2004; Perrin et al., 2009): from plankton- to marine mammal-eating species, from tropical to polar regions, from species foraging at the sea surface to those hunting over a thousand metres deep and from resident to migrating species. The main difference between cetaceans and either seabirds or pinnipeds relates to reproductive strategies; the latter two require land to breed or moult (Gaston, 2004; Perrin et al., 2009), while cetaceans have evolved a completely marine lifestyle (Chivers, 2009). Terrestrial reproduction and moulting have major consequences for seabirds and pinnipeds as they induce central-place foraging constraints, by which these species must rely on food available within a short distance from colonies and resting sites, whereas they can range freely the rest of the year (Gaston, 2004; Perrin et al., 2009).

Although studies on the habitat of homeotherm marine predators are now common, especially over shelf areas, they often focus on short temporal scales due to methodological constraints (but see Ballance et al., 2006; Forney et al., 2015; Becker et al., 2016), which results in only a few investigations addressing the consistency of habitat preferences over time. However, some species may be expected to use several habitats depending on their availability and quality, while other species might be specialised towards a specific habitat type year after year.

Since 2004, the PELGAS ("PELagique GAScogne") oceanographic survey has been conducted in May in the Bay of Biscay (BoB; eastern North Atlantic) to study the ecosystem from physical oceanography to top predator ecology (Doray et al., 2018, ; this issue). This survey represents a unique opportunity to explore the temporal variability of species relationships to their habitats in a diversified top predator community, composed of species with contrasted lifestyles. The BoB is located at the intersection of cold and warm temperate biogeographic regions and is characterised by the occurrence of species with warm water as well as cold water affinities.

In this study, we focused on five cetacean and seabird taxa frequently encountered in the BoB (the sighting surveys were not appropriate for spotting pinnipeds). Bottlenose (Tursiops truncatus) and common dolphins (Delphinus delphis) are two species that are widely distributed, from estuaries to offshore waters. In the BoB, we know from previous studies in spring that bottlenose dolphins are aggregated over the slope, while common dolphins can also be encountered over the shelf (Certain et al., 2011). At the western Europe scale, bottlenose dolphins mostly occur over the slope in both winter and summer while common dolphins are abundant over the shelf in winter but are more widespread from shelf to oceanic waters in summer (Lambert et al., 2017, which focused on one-year seasonal ecological preferences of cetaceans and seabirds in the eastern North-Atlantic). Northern fulmars (Fulmarus glacialis) and auks (common guillemot Uria aalge and razorbill Alca torda) are two taxa with cold water affinities. The BoB represents the southern part of their range during both breeding and wintering periods (Lambert et al., 2017), and despite we know auks are more aggregated along the coast while 
fulmars are widespread over the shelf but avoid coastal waters (Certain et al., 2011; Lambert et al., 2017), information on their at-sea ecology remains poor. The northern gannet (Morus bassanus) is a more widely distributed species, breeding in northern Europe but wintering from the North Sea to western Africa (Nelson, 2002; Fort et al., 2012; Lambert et al., 2017). Although the species must face strong intra-specific competition during the breeding season, leading to sharp habitat preferences, during the wintering period gannets exhibit some flexibility with wintering grounds having different characteristics (for example, the Canary Current or the English Channel; Fort et al., 2012; Lambert et al., 2017).

In the BoB and during the PELGAS surveys, which occur during their breeding period, most of sighted auks and gannets are supposed to be non-breeders, the number of breeding auks being very low in the area (Cadiou et al., 2014) and the closest colony of gannets being in the English Channel (Nelson, 2002). Thus, the present study will provide valuable information on a poorly-known fraction of seabird populations, the non-breeding individuals (either juveniles or non-breeding adults).

Previous studies explored the averaged spatial distribution of predators over the 2003-2008 time period in the BoB (Certain et al., 2011) or unveiled the ecological preferences at the western Europe scale by contrasting winter and summer seasons (Lambert et al., 2017), but none focus on the long-term temporal variability of ecological preferences of predators. Thus, this study complements the knowledge brought by Certain et al. (2011); Lambert et al. (2017) on the habitat preferences of predators in the BoB by explicitly investigating the temporal variability of their springtime habitat preferences, thanks to the long time period of the PELGAS surveys. As suggested above, we expected two main patterns: (i) specialist species using the same pelagic habitat year after year, spatial variations of distribution reflecting spatial variations in habitat availability and (ii) species exhibiting a great variability in habitat preferences over time, either because generalist species are made up of specialist individuals with different habitat preferences, or because all individuals are generalists and remain within the same area irrespective of whether the corresponding habitat had changed.

We used in-situ environmental variables and top predator observational data collected during the decadal oceanographic surveys conducted in May every year from 2004 to 2013 within the BoB. We first characterised the habitats available in the study area in May. Given their dynamic nature, pelagic habitats are often difficult to define and distinguish (Barry \& Dayton, 1991; Longhurst, 2007), but we chose to identify the different habitats available as well as their interannual variations, using a Principal Component Analysis (PCA). Springtime habitat preferences were explored with habitat modelling (generalized additive models (GAMs); Guisan \& Zimmermann, 2000), highlighting potential associations to specific environmental conditions and their variation over time.

\section{Material \& Methods}

\subsection{Study area}

The $\mathrm{BoB}$ is a large bay in the eastern North Atlantic, spanning from France to Spain (Figure 1). This bay is characterised by a broad continental shelf, which extends from $180 \mathrm{~km}$ in the northern part of the BoB, to $20 \mathrm{~km}$ in the southern part (Capbreton Canyon) and approximatively 30-40 km wide along the Iberian coasts (Koutsikopoulos \& Le Cann, 1996). The oceanic part of the BoB is 2,000-5,000 m deep. In the southern $\mathrm{BoB}$, the interaction between the slope current flowing from Iberian Peninsula to the northern BoB and the shelf break topography frequently results in meso-scale eddies that are relatively persistent in time (Pingree \& Le Cann, 1992; Caballero et al., 2014). Over the shelf, currents are mainly driven by winds, tides or freshwater inputs, depending on the area (Koutsikopoulos \& Le Cann, 1996). Seasonality is well marked, with a thermal stratification establishing during spring from south to north (Koutsikopoulos \& Le Cann, 1996) and phytoplankton blooms occurring during the same period (Pingree \& Garcia-Soto, 2014). 


\subsection{Survey data}

The study was based on the PELGAS pelagic oceanographic surveys, conducted by Ifremer onboard the R/V Thalassa, to study the abundance and distribution of small pelagic fish and monitor the BoB pelagic ecosystem. These surveys have been conducted every spring since 2000, along fixed parallel transects from the coast to the shelf break, orthogonal to the main isobaths (Figure 1, Doray et al., 2018). Effective sampling design and total survey effort vary each year depending on the annual extent of the survey, sometimes extending farther than the shelf edge. However, in the present study, we conducted the analyses on the area commonly sampled every year to determine variability in the same area.

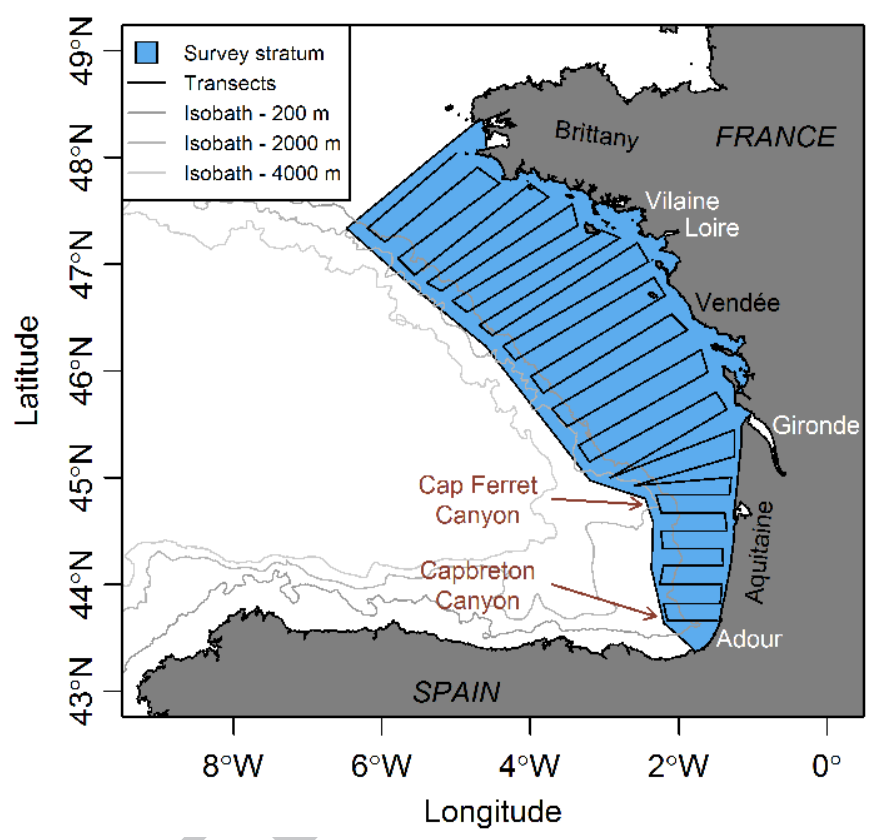

Figure 1. Survey area and theoretical sampling design of the PELGAS survey. The isobaths are indicated in grey, the four main estuaries in white, the geographical localities in black and the main canyons in brown.

Standardised top predator observations were collected from 2004 to 2013 following a line transect protocol (Buckland et al., 2001). Effort spanned from sunrise to sunset whenever the vessel was moving at $\geq 8$ knots and stopped during trawling The main observation platform was the upper deck of the $\mathrm{R} / \mathrm{V}$ Thalassa (16 $\mathrm{m}$ above sea level), but when weather deteriorated (strong winds or rain), the observation platform was changed to the ship bridge (14 m above sea level). Two trained observers scanned with naked eyes $180^{\circ}$ ahead of the bow, with each observer scanning $90^{\circ}$ on each side of the bow. The period of observation was no longer than two hours. Observation conditions (Beaufort sea-state, swell, glare, cloud cover, platform) were recorded every hour, or whenever observation conditions changed. For each sighting, species composition, number of individuals, behaviour, distance and angle to the observer were recorded. Individuals attending either the vessel or fishing vessels operating nearby were not recorded. In situ environmental variables, such as surface and bottom temperature, salinity, mixed layer depth and surface chlorophyll a concentration were routinely collected along transects (Doray et al., 2014).

\subsection{Habitats characterisation}

To explore the different habitats available and variations of their spatial extent over the decade, we performed a PCA on environmental data (Figure 2). This technique allows environmental conditions to be summarised to identify environmental structure by maximising data variance. In situ variables available for all years were compiled over a $0.25^{\circ}$ grid (Appendix A). They include sea surface temperature (SST), temperature near seabed (SBT), mixed layer depth (MLD) and sea surface salinity (SSS). SST gradient (SSTg) was computed 
over the same grid as the largest difference between each cell and its neighbours. Depth and slope aspect were summarised in the same way from the GEBCO database. Surface chlorophyll concentrations measured in situ were not available over the whole area for the whole decade. Instead, we used MODIS monthly composite surface chlorophyll a (CHL) concentration (in May, http://oceancolor.gsfc.nasa.gov), and Eppley-VGPM net primary productivity (NPP) at the same temporal resolution (http://www.science.oregonstate.edu/ ocean.productivity). These two variables were summarised over the PELGAS grid. These grid cells were used as samples for the PCA, and the environmental variables were scaled to unit variance for standardisation. Although the standard NASA algorithm, designed to derive chlorophyll-a in the open ocean, is not fully adapted to the continental shelf of th BoB (Tilstone et al., 2017), it has been used here as a proxy.

We performed a hierarchical cluster analysis on the PCA result to identify habitats available in the BoB. The number of clusters was determined based on the tree constructed from the previously estimated Principal Components (PC). The inferred clusters were plotted each year to visually assess their spatial variations. PCA was carried out in R version 3.2.3 (R Core Team, 2015) with the package FactoMineR (Husson et al., 2016), and the hierarchical cluster analysis was carried out with the function hclust using the "ward.D" method.

\subsection{Species habitat preference per year}

Habitat preferences over the decade were analysed for five taxa frequently encountered in the BoB during PELGAS surveys. These taxa included two cetaceans and three seabirds: bottlenose dolphin, common dolphin, guillemot and razorbill, northern fulmar, and northern gannet.

Sighting data were aggregated to match the $0.25^{\circ}$ grid format of environmental covariates. We summed the numbers of observed individuals per cell as well as the effort deployed in each cell by multiplying the lengths of all segments falling within a cell by twice the effective strip width (ESW) of each species (see Appendix B for details about distance sampling analyses). Habitat preference analyses were performed only with effort realised under Beaufort sea-state lower than 4 and subjective conditions excellent to medium. All sightings of individuals attracted or repelled from the boat were removed, as well as individuals coming to the bow, scavenging behind fishing vessels or coming from the back of the observation platform.

To explore springtime habitat preferences, habitat modelling was performed using GAMs (Figure 2, Wood, 2011) relating the number of individuals (response variables) to environmental predictors through a logarithmic link function with the Tweedie error distribution, and the sampled area as an offset.

Two types of models were used (Figure 2). First, a global model (i.e. a baseline model supposing no variation across years, providing "mean" preferences) included the three main PCs as well as the distance to the closest colony for seabirds (see Appendix A; using thin plate regression splines as smoothers). Second, an interaction model included the same four variables but with year as an interaction term (using full tensor product smooths). The inclusion of year as an interaction term allowed the relationships between response variable and covariates to differ for each year. The maximum degree of freedom for smoothers was constrained to 3 to avoid over-fitting the data. The $\mathrm{R}$ code for the two types of models is shown in Appendix C. Explained deviances and Akaike information criterion (AIC) as well as p-values were examined to identify the best models. From the best-performing model, predictions were made for each year.

To explore whether the identified environmental preferences resulted in preferential associations to any of the three habitats identified in the $\mathrm{BoB}$, we extracted the abundance within each habitat cluster and related it to its respective surface for each year. These predicted densities were scaled by the maximum density that was predicted within the $\mathrm{BoB}$ for each year, providing annual predicted relative densities by habitat cluster.

The model fitting process and the predictions were done with R 3.2.3 (R Core Team, 2015), using the mgcv package (Wood, 2011), while the extraction of relative density within available habitats were calculated in $\mathrm{R}$ 2.15.3, using the raster package (Hijmans et al., 2014). 


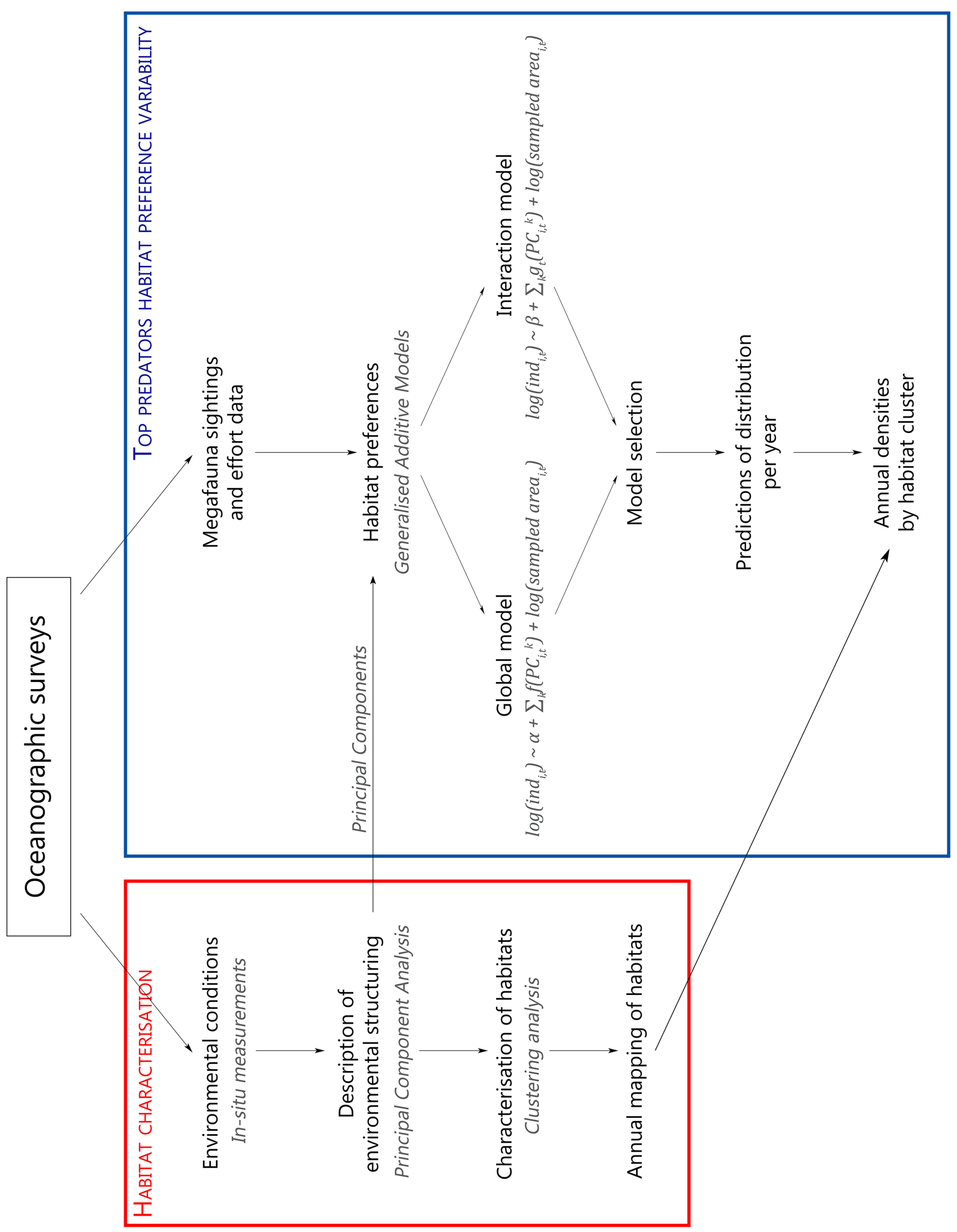

Figure 2. Flowchart of the several methodological steps used within this study. The equations are the formulations of the two tested generalized additive models, with $\log \left(i n d_{i, t}\right)$ the response variable, $\alpha$ and $\beta$ the intercept values for global and interaction models (respectively), $\sum_{k} f\left(P C_{i, t}^{k}\right)$ and $\sum_{k} g_{t}\left(P C_{i, t}^{k}\right)$ the additive functions of environmental parameters (here, the Principal Components (PC) and distance to the closest colony) for global and interaction models (respectively), and $\log \left(\right.$ sampledarea $\left._{i, t}\right)$ the offset; with $i$ the grid cell, $t$ thg year and $k$ the PC. $f()$ is a thin plate regression spline, $g()$ a full tensor product smooth; only $g()$ explicitly includes time, as an interaction term on environmental variables. 


\section{Results}

\subsection{Habitats characterisation}

The first three PCs accounted for $68.7 \%$ of the variance of the data. The first PC explained $36.0 \%$ of the variance, the second PC $17.1 \%$ and the third PC 15.7\% (Figure 3a). The first PC (PC 1, Figure 3b, c) was mainly related to SSS, bathymetry and slope with higher values to the right end of the axis, as well as to CHL and NPP with higher values to the left end of the axis, indicating that shallow waters with low salinity were more productive than deep waters with high salinity. The second PC (PC 2, Figure 3b, d) was mainly related to temperature (SST, SSTg and SBT). The MLD was similarly important over the two PCs, with negative correlation to CHL/NPP for the first PC, and negative correlation to temperature for the second PC. For the third PC (PC 3, Figure 3c, d), all variables loaded positively, except MLD and SSS.

(a)

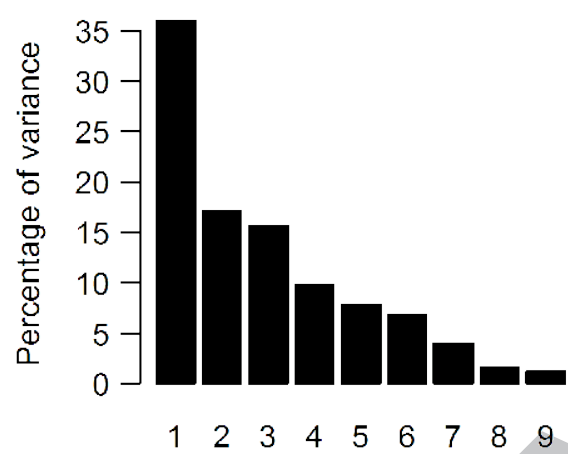

Eigen values

(c)

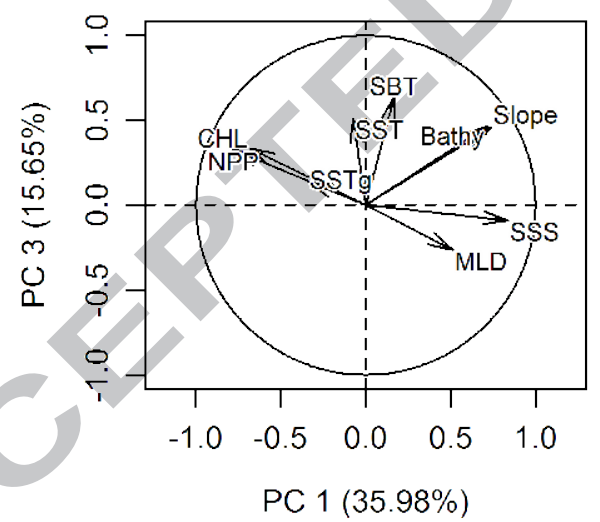

(b)

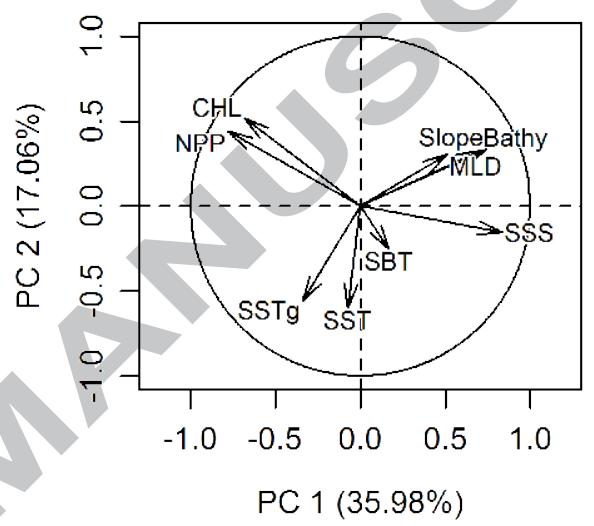

(d)

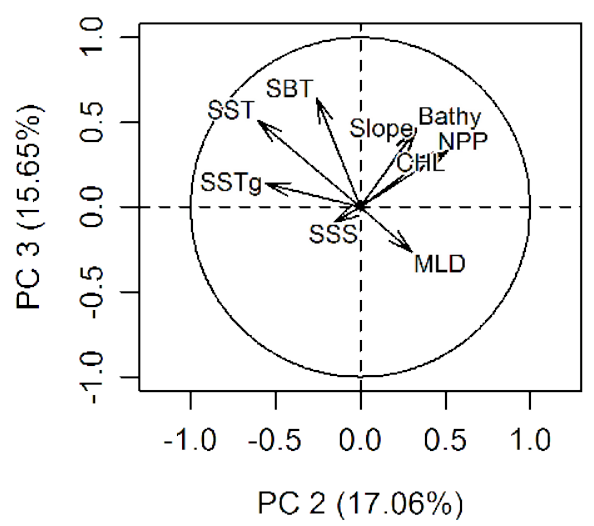

Figure 3. Results of the Principal Component Analysis (PCA): (a) percentage of variance explained by each of the nine eigen values; (b) PCA correlation circle for the first and second Principal Components (PCs); (c) PCA correlation circle for the first and third PCs; (d) PCA correlation circle for the second and third PCs. SST: Sea Surface Temperature; SSTg: SST gradients; SBT: Sea Bottom Temperature; SSS: Sea Surface Salinity; MLD: Mixed Layer Depth; CHL: surface chlorophyll a concentration; NPP: Net Primary Production.

The hierarchical cluster analysis of the PCA suggested three main clusters (Figure 4a). These clusters were mostly separated on the first PC (Figure 4b-d): (A) shallowest waters with lowest salinities, and highest NPP and CHL; (B) waters with shallower depth, lower slope/CHL/NPP and higher SST compared to the averaged situation and (C) deepest waters associated with steep slope and high salinities, as well as lower CHL/NPP. Clusters A and B corresponded to the BoB shelf area, the former being related to coastal and productive habitats mainly associated with river plumes, the latter corresponding to central shelf waters with lower CHL/NPP. The third cluster corresponded to the shelf break (Figure 4), as indicated by the steep slope, high depth and salinity. Overall, these three habitats were distributed from east to west in the area, but their spatial extent varied 
depending on the year. For example, the habitat 1 was almost absent in 2011, but extended widely across the shelf in 2004, while habitat 3 spread farther over the shelf in 2004, 2005 and 2010 compared to the other years (Figure 5). On the second axis, driven by the SST, clusters A and C were both colder than cluster B.

(a)

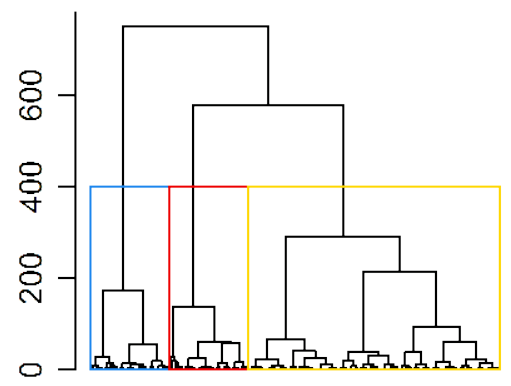

(c)

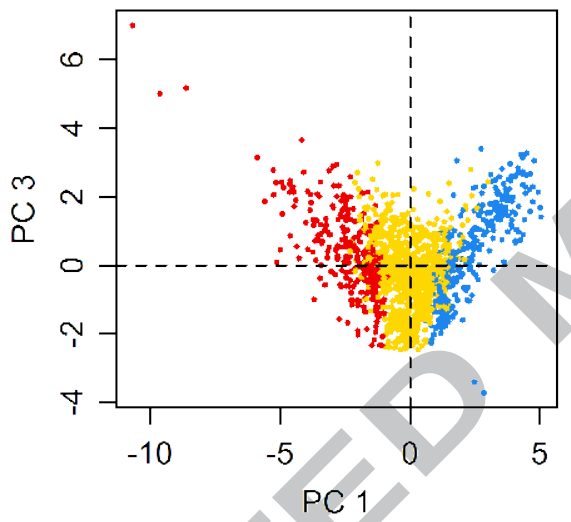

(b)

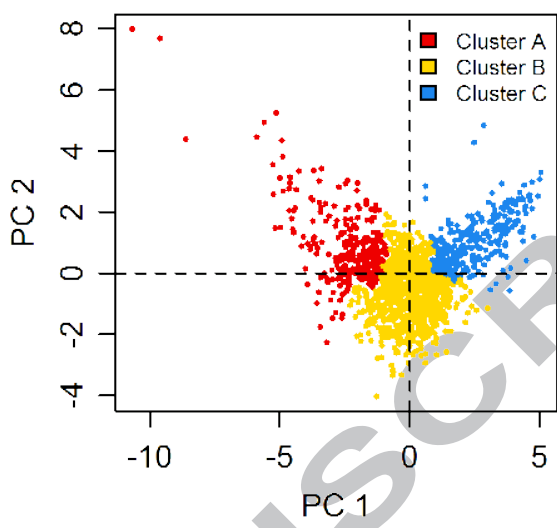

(d)

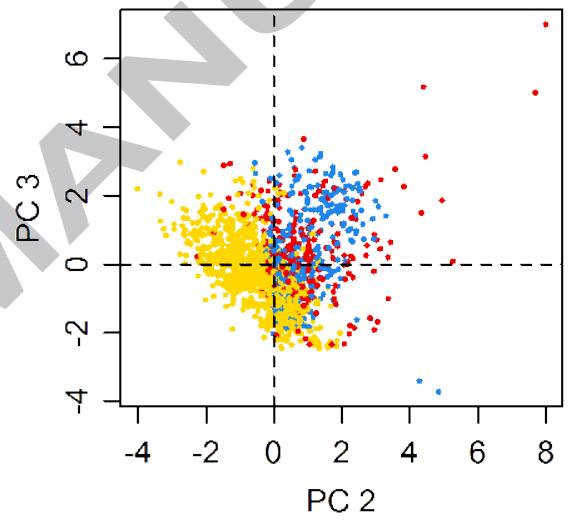

Figure 4. Hierarchical cluster analysis results using the three first Principal Components (PCs): (a) dendrogram and the three clusters identified; (b) clusters in the plane (PC1, PC2); (c) clusters in the plane (PC1, PC3); (d) clusters in the plane (PC2, PC3). Cluster A: river plumes; cluster B: shelf; cluster C: shelf edge.

\subsection{Sighting data}

Over the PELGAS surveys, yearly encounter rates (number of individuals sighted per $100 \mathrm{~km}$ of effort) were relatively low for most species (Table 1), except for the northern gannet, which was the most sighted species with up to 4 individuals sighted per sampled $100 \mathrm{~km}$. However, the distributions of sightings showed strong spatial patterns (Figure 6), with some variations among years (see Appendix D for sightings and density maps per year). Overall, fulmars were mostly found over the outer shelf in the northern BoB; gannets were widely dispersed over the entire BoB; auks were concentrated along the coast; common dolphins were found over the whole shelf, especially in the central part; and bottlenose dolphins were mostly encountered along the southern shelf edge (Figure 6).

\subsection{Species habitat preference per year}

There is one average value per year per group for each variable allowing the inter-annual variability to be represented in boxplots 


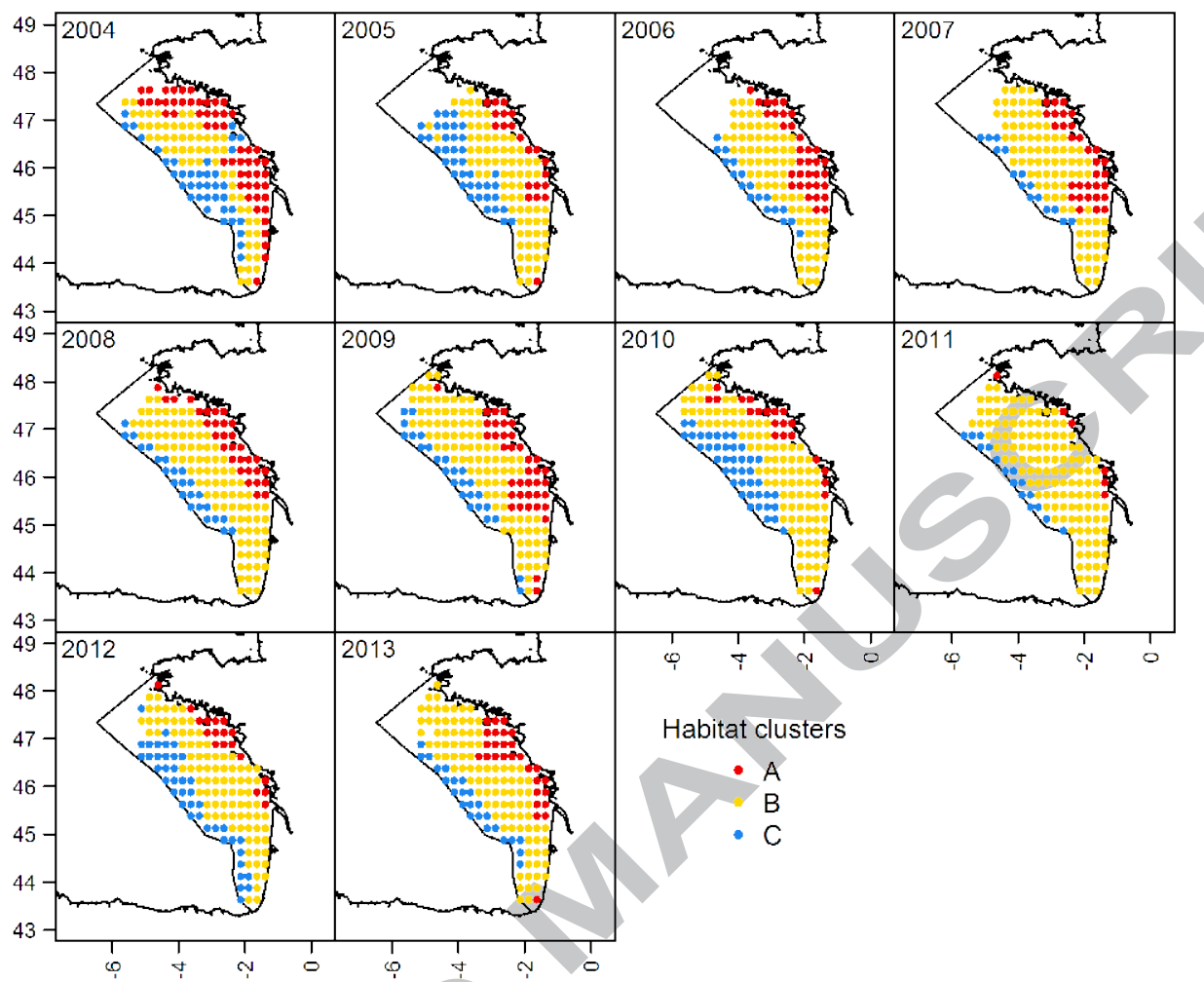

Figure 5. Yearly variations of the spatial extent of the three habitats available over the Bay of Biscay from 2004 to 2013. Cluster A: river plumes; cluster B: shelf; cluster C: shelf edge.

Table 1. Encounter rates from 2004 to 2013, in individuals per $100 \mathrm{~km}$ of effort.

\begin{tabular}{cccccc}
\hline Year & Bottlenose dolphin & Common dolphin & Auks & Northern fulmar & Northern gannet \\
\hline 2004 & 0.011 & 0.200 & 0.139 & 0.149 & 1.229 \\
2005 & 0.605 & 0.573 & 0.096 & 0.213 & 1.599 \\
2006 & 0.413 & 0.467 & 0.101 & 0.200 & 2.596 \\
2007 & 0.525 & 0.019 & 0.189 & 0.320 & 0.757 \\
2008 & 0.453 & 1.951 & 0.693 & 0.661 & 4.145 \\
2009 & 1.250 & 1.426 & 0.285 & 0.360 & 1.312 \\
2010 & 0.440 & 0.733 & 0.336 & 0.515 & 1.591 \\
2011 & 0.157 & 0.597 & 1.002 & 0.219 & 0.520 \\
2012 & 0.080 & 0.672 & 0.291 & 0.160 & 1.618 \\
2013 & 0.307 & 0.573 & 1.778 & 0.133 & 4.239 \\
\hline
\end{tabular}




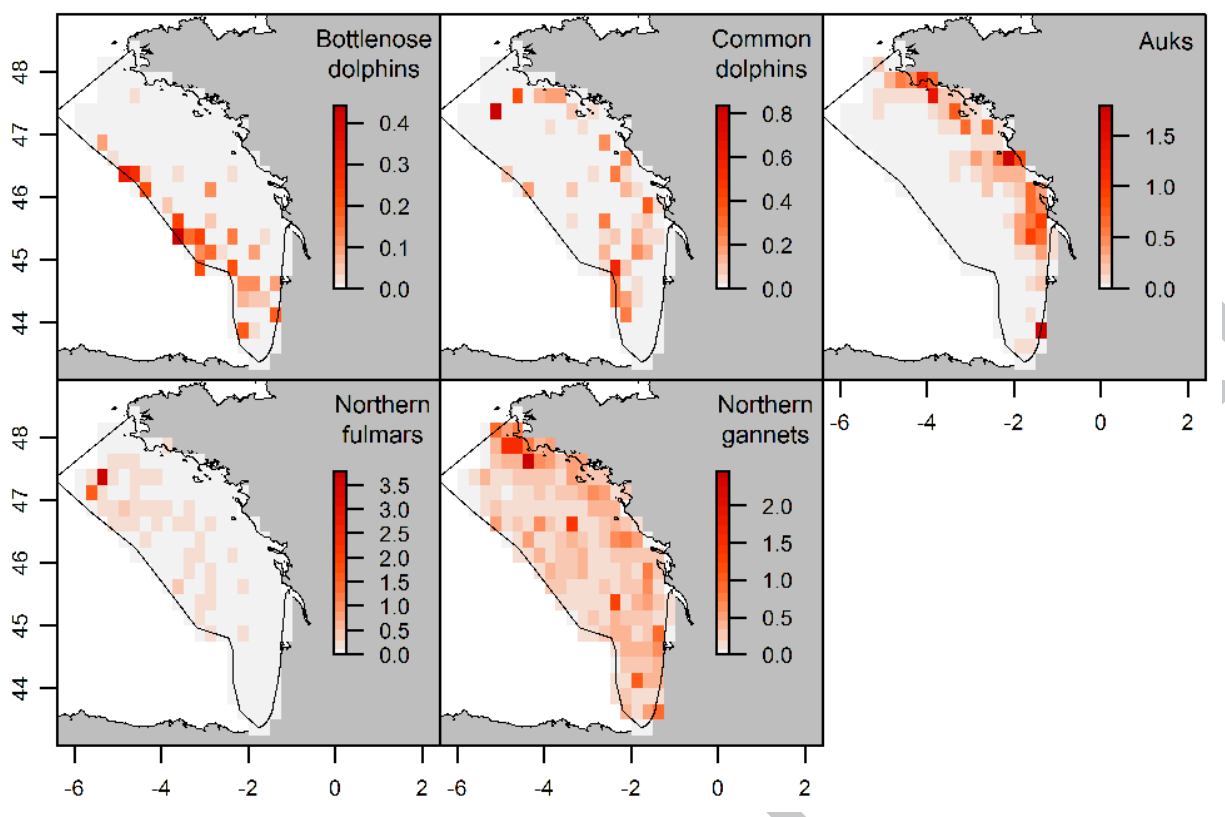

Figure 6. Mean sighted densities (individuals per sampled $\mathrm{km}^{2}$, with effort corrected for detection) for the studied groups of species from 2004 to 2013.

Table 2. Generalised Additive Model results for the five studied species. The explained deviances (in \%) and the significance levels for the four covariates are given, as well as the model AICs for the global model and the interaction model. PC: Principal Component. ${ }^{* * *}$ : p-value $\leq 0.001 ; * *$ p-value $\leq 0.01 ; *$ : p-value $\leq 0.05$.

\begin{tabular}{|c|c|c|c|c|c|c|}
\hline & & $\begin{array}{l}\text { Bottlenose } \\
\text { dolphin }\end{array}$ & $\begin{array}{c}\text { Common } \\
\text { dolphin }\end{array}$ & Auks & $\begin{array}{l}\text { Northern } \\
\text { fulmar }\end{array}$ & $\begin{array}{c}\text { Northern } \\
\text { gannet }\end{array}$ \\
\hline \multirow{6}{*}{ Global model } & Explained deviance (\%) & 32.9 & 11.0 & 35.0 & 21.8 & 18.2 \\
\hline & $\mathrm{PC} 1$ & $* * *$ & & $* * *$ & $* * *$ & $* * *$ \\
\hline & $\mathrm{PC} 2$ & & & & & $*$ \\
\hline & PC 3 & $* * *$ & & $* * *$ & $* *$ & $* * *$ \\
\hline & Distance to closest colony & & & & $* * *$ & $* * *$ \\
\hline & $\mathrm{AIC}$ & 1586.8 & 1739.3 & 2469.3 & 2783.0 & 6408.4 \\
\hline \multirow{6}{*}{ Interaction model } & Explained deviance (\%) & 37.9 & 13.0 & 54.1 & 34.5 & 34.9 \\
\hline & $\mathrm{PC} 1$ & $* * *$ & & $* * *$ & $* * *$ & $* * *$ \\
\hline & $\mathrm{PC} 2$ & & & $* * *$ & $* * *$ & $* * *$ \\
\hline & PC 3 & $* * *$ & & $* * *$ & $* * *$ & $* * *$ \\
\hline & Distance to closest colony & & & $* * *$ & $* * *$ & $* * *$ \\
\hline & $\mathrm{AIC}$ & 1588.5 & 1737.1 & 2335.0 & 2657.0 & 6149.8 \\
\hline AIC(global model & - AIC(interaction model) & -1.7 & 2.2 & 134.3 & 126.0 & 258.6 \\
\hline
\end{tabular}


(a)

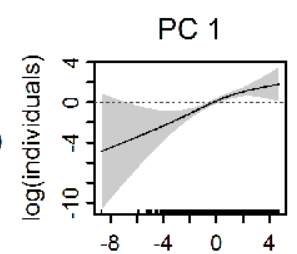

(b)

$\frac{\widehat{D}}{\frac{0}{3}}$
$\frac{\bar{y}}{2}$
$\frac{\overline{0}}{\overline{0}}$
$\underline{0}$

(c)

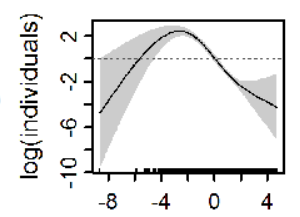

(d)

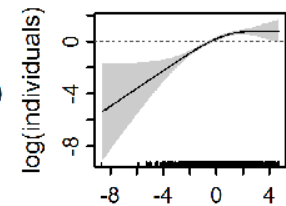

(d)

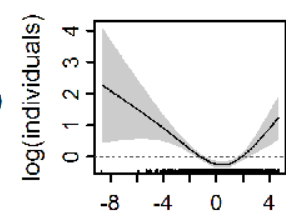

PC 2

N.S.

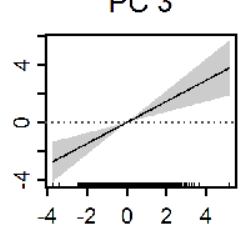

N.S.

N.S.

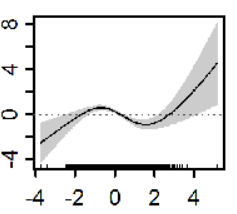

N.S.
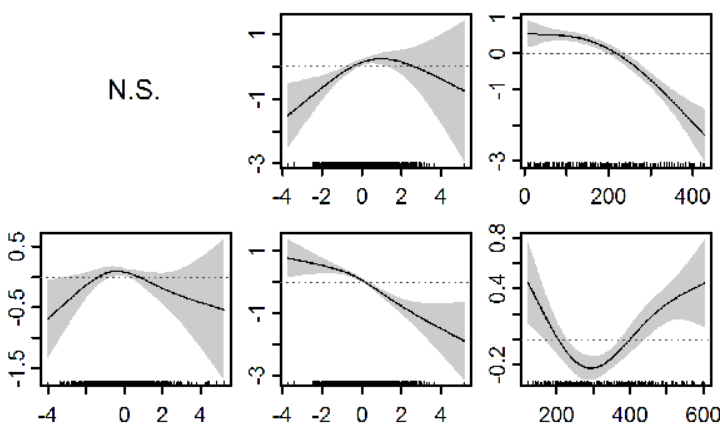

Distance to

closest colony

N.S.
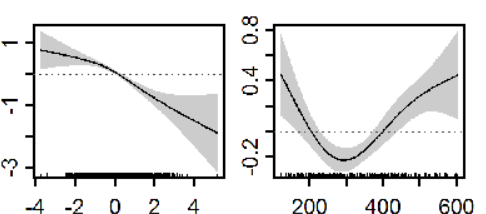

Figure 7. Generalised Additive Models (global models) for (a) bottlenose dolphins, (b) common dolphins, (c) auks, (d) northern fulmars and (e) northern gannets. The curves are given for significant variables (N.S. = non significant) and represent the relationship between the covariate (abscissa) and the linear predictor ( $\log ($ individuals), ordinate). The covariates are the three first Principal Components (PC) of the Principal Component Analysis, and the distance to closest colony for seabirds. 


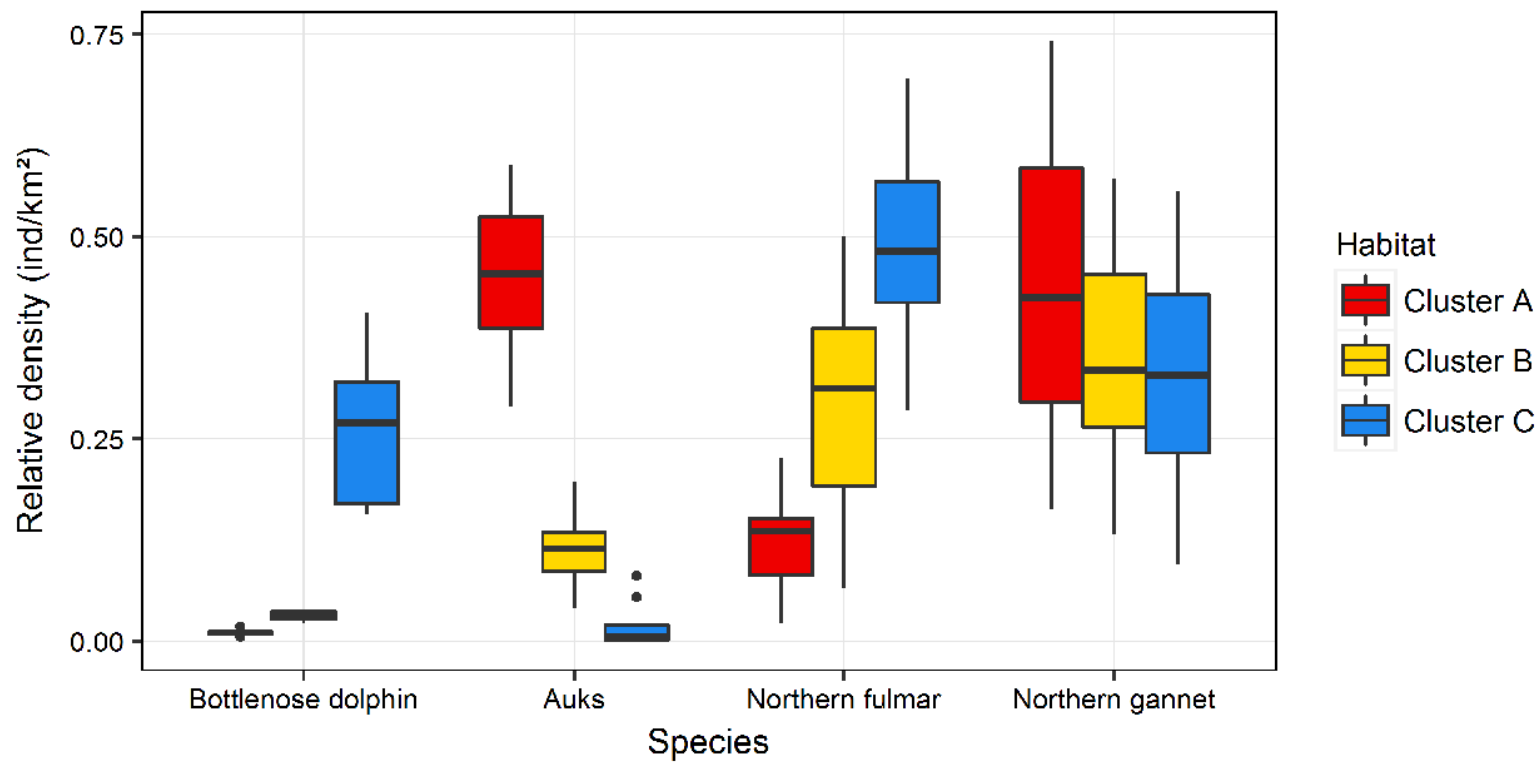

Figure 8. Annual relative densities by habitat cluster for bottlenose dolphins, auks, northern fulmars and northern gannets. There is one density value per year by cluster by species, so that box-plots represent the inter-annual variability of density by habitat cluster. The differences of densities and dispersion across the three clusters by species summarise the degree of specificity in their habitat preferences (non-overlapping box-plots: strong specificity of habitat preference; overlapping box-plots: low specificity of habitat preference). Cluster A: river plumes; cluster B: shelf; cluster C: shelf edge.

\subsubsection{Bottlenose dolphins}

The global model for bottlenose dolphins reached $32.9 \%$ of explained deviance (AIC = 1586.8), with PCs 1 and 3 as significant variables (Table 2). The relationships to these two PCs were increasing, with positive densities of dolphins associated with positive values of both PCs. (Figure 7a).

The interaction model exhibited the same significant variables, for an explained deviance of $37.9 \%$ (AIC $=1588.5$; Table 2). According to the difference in AIC, the interaction model was slightly less parsimonious than the global one, despite the improvement of explained deviance. In addition, as the AIC difference was negligible, we favoured the simplest model and chose the global model as the best model. According to the predicted distribution and the predicted densities by cluster, the bottlenose dolphins were clearly associated with habitat cluster C, with almost no variations among years (Figure 8; Appendix E1). In 2007-2008 and 2011 however, substantially high relative densities were also predicted over the shelf (cluster B).

\subsubsection{Common dolphins}

The global model explained $11 \%$ of deviance $(\mathrm{AIC}=1739.3)$ but none of the three covariates was statistically significant (Table 2). Indeed, all estimated relationships were flat (Figure 7b). The interaction model did not improve model fit, with only $13 \%$ of explained deviance (AIC $=1737.1$ ), and none of the variables were statistically significant (Table 2, Figure 7). Both models failed to provide reliable predictions compared to observations and no further inferences were carried out on common dolphins (see Appendix E2).

\subsubsection{Auks}

The global model for auks explained $35 \%$ of the deviance $(\mathrm{AIC}=2469.3)$, with PCs 1 and 3 significant (Table 2$)$. Positive densities of auks were associated with negative values of the PC 1 , and positive values of the PC 3 (Figure 7c). The explained deviance of the interaction model reached $54.1 \%(\mathrm{AIC}=2335.0$ ), and all variables were significant (Table 2). Given the increase in explained deviance, the reduction of the AIC and the significance of all variables, the interaction model was selected as best model. 
Although the selection of the interaction model implied some variations across years, the predicted distributions were similar across years, as was the preferential association to identified habitats (Figure 8), with an increase in auk density over the decade (Appendix E3). Overall, auks were consistently associated with habitat cluster A, and their yearly distributions closely matched the spatio-temporal variations of this habitat. Spatial variations were associatedwith river plumes, where auks were most often sighted. For example, in 2009, higher relative densities were associated with the Loire river plume and in 2013, they were associated with the Gironde river plume.

\subsubsection{Northern fulmars}

The global model resulted in an explained deviance of $21.8 \%$ ( $\mathrm{AIC}=2783.0)$, with PCs 1 and 3 as well as distance to the closest colonies as significant variables (Table 2). The relationship to the PC 1 increased with positive densities of fulmars being associated with positive values of this PC. The relationship to the PC 3 was unimodal, with a maximum at null values of the PC. The relationship to distance to the closest colony was decreasing, with positive densities of fulmars for distance to the colony $\leq 200 \mathrm{~km}$ (Figure 7d).

In the interaction model, the four interaction terms were significant and the model explained $34.5 \%$ of the deviance (AIC $=2657.0$; Table 2). The significance of the interaction terms and the higher explained deviance indicated that the relationship described above varied among years. Given this result and the clear improvement of the AIC, the interaction model was selected as best model, and predictions were computed annually.

Consistent with the significant year effect, differences among years were predicted in distribution (Appendix E4). Fulmar predicted densities increased while going offshore: densities were higher along the shelf edge and fulmars were absent from river plumes and from the southern part of the BoB. Some variations occurred among years, for example the species was more widespread towards the south in 2005-2007 and more restricted to the northern BoB in 2011-2013. This difference may be linked to annual variations in the relationship to distance to the closest colony.

The results from predicted distributions were mirrored by the predicted densities by habitat clusters (Figure 8), which showed a preferential association to the habitat cluster $\mathrm{C}$, with gradually decreasing densities from habitat cluster $\mathrm{C}$ to $\mathrm{A}$.

\subsubsection{Northern gannets}

The global model for northern gannets explained $18.2 \%$ of the deviance $(\mathrm{AIC}=6408.4)$, with all terms being significant (Table 2). The relationships to PCs 1 and 2 were both unimodals, with a minimum at null values for the PC 1 and a maximum at null values for PC 2. The relationship was decreasing for the PC 3, with gannet positive densities being associated with negative values of PC 3 . The relationship to distance to closest colony was also unimodal, with negative densities of gannets associated with distances of 200-400 km from colonies (Figure 7e).

The inclusion of the year as an interaction term clearly improved the model, with $34.9 \%$ of explained deviance, which was an improvement of the AIC of 258.6 points (AIC $=6149.8)$, and all terms were significant (Table 2). Thus, this model was selected as the best model. Predicted distributions and densities by habitat (Appendix E5) clearly showed the strong year effect. Overall, a slight preference for habitat cluster A to C emerged, but with extensive yearly variations (Figure 8, Appendix E5); for example, in 2007, gannet habitat preference went from habitat cluster $\mathrm{C}$ to A, while in 2012 there was no difference between the three habitats. In all cases, the difference in densities between habitats was low, and the species was present everywhere. 


\section{Discussion}

\subsection{Methodological considerations}

To explore the variations in springtime habitat preferences of five mobile top predator species over a decade (2004-2013), we first described the habitats available within the BoB with a PCA, which is a conventional method to describe and highlight relationships between a set of variables (Jongman et al., 1995). Second, we inferred the habitat preference of studied predators and focused on the stability with which predators were associated with specific habitat over the decade.

In this study, the use of PCA as an input of habitat modelling resulted in higher quality models and predictions than more "traditional" habitat models that use raw environmental variables (not shown). PCA is a data reduction technique, where raw data are projected onto new orthogonal axes called PCs that are uncorrelated and with maximum variance. These PCs are linear combinations of the raw variables and provide two main advantages for habitat modelling: (i) the number of variables included in models is reduced (here, from nine to three); (ii) using PCs removes collinearity issues between environmental covariates (e.g., between CHL and NPP, or depth and slope).

A drawback of this method is that the interpretation of PCs in terms of environmental variables may be difficult (large number of variables). Fortunately, in our study, the interpretation of PCs was facilitated by considering the habitats identified on each PC by the cluster analysis, rather than the raw environmental variables combinations. For example, the first PC can be interpreted more easily as corresponding to the shelf edge at one side and river plumes at the other, rather than high depth, steep slopes and low salinity versus high CHL, NPP and salinity

Moreover, as for the PCA we used only environmental variables to which the studied predators are known to be linked (based on literature), all the covariates available were used when fitting habitat models with GAMs (the three PCs and the distance to the closest colony), without implementing any selection procedure.

\subsection{Pelagic habitat availability}

Based on the PCA, we identified three main pelagic habitats in the BoB and visualized year-to-year variability in habitat spatial extent, that is their availability (Figures 4 and 5). PCA highlighted two independent environmental gradients in the $\mathrm{BoB}$ (PCs 1 and 2), accounting for $53 \%$ of data variance and separating pelagic waters into three main habitats. The first gradient separated river plumes (habitat cluster A), characterised by high values of CHL/NPP and low SSS, from the shelf edge (habitat cluster C), characterised by high depth, steep slopes and high SSS.

The second gradient was independent from the previous gradient and was mainly driven by temperaturerelated variables. This second gradient did not separate the first two habitats, which were both characterised by cold waters, but isolated a third habitat, corresponding to the central shelf (habitat cluster B) with relatively warmer temperature and intermediate values of CHL/NPP and depth/slope. Habitat clusters A and C were both characterised by low SST. River plumes had low SST due to freshwater inputs (Jegou \& Lazure, 1995), and slope was associated with upwelling of colder deep oceanic water because of internal waves (Green et al., 2008).

Habitat cluster C, because it was mostly associated with a topographic feature, showed little spatial variation between years, although it spread farther over the shelf in particular years (2004-2005, 2010). Habitat cluster A was associated with a more dynamic feature, and its extent varied extensively among years. The extent of river plumes depends on freshwater run-off, i.e. on the rainfall over drainage basins during previous months, as well as on wind patterns. For example, habitat cluster A was almost absent in 2011, when river plumes were reduced due to severe rainfall shortage in April that year, while in 2009, strong winds contributed to extend river plumes offshore. 


\subsection{Top predator response to decadal spatio-temporal variability of available habi- tats}

Comparing models with year as an interaction term and without year as an interaction term allowed for an assessment of whether springtime habitat preferences of species varied among years. Our results showed a range of patterns depending on the specificity and stability of species preferences, which highlighted species-specific habitat flexibility. The species exhibiting the narrower habitat preferences also exhibited stronger stability in their preferences among years (bottlenose dolphins and auks) while the species with wider habitat preferences exhibited higher variability among years (gannets).

The most extreme case of habitat preference variability was for the bottlenose dolphin, which was confined to the shelf edge during all years, with densities one order of magnitude higher within habitat cluster $\mathrm{C}$ compared to the other two habitats. This preference was in line with the known distribution of the species in the area from large-scale surveys (Certain et al., 2011; Lambert et al., 2017), which all showed a clear preference of bottlenose dolphins for the shelf edge in the area, whatever the season and year. Nevertheless, the model predicted some bottlenose dolphin expansion over the shelf, especially in 2007-2008 and 2011, which was also in line with previous results, as some intrusions over neritic waters was also demonstrated in 2011 and 2012 (Lambert et al., 2017).

Auks also exhibited a sharp preference for habitat cluster A, corresponding to river plumes. However, unlike bottlenose dolphins, some differences occurred among years. Although the inclusion of year in the model was compatible with the increase in overall abundance over the decade, auks also exhibited year-to-year differences in their use of river plumes (some years, highest densities were in the Gironde estuary, in other years highest densities were in the Loire estuary). Despite these small variations, the distribution of auks was mostly linked to spatial variations of habitat A, but when this habitat was reduced or particularly contracted, as in 2010-2012, the species occurred in surrounding habitat B as well.

As much as $91.6 \%$ auk sightings were of common guillemots, while only $2.0 \%$ were of razorbills and $6.4 \%$ sightings were unidentified alcids. The number of breeding pairs of common guillemots in local colonies is very low, with only 14 individuals on average between 2000 and 2011 (Cadiou et al., 2014); thus most auks sighted within the BoB during the survey period were likely non-breeders. The presence of non-breeders is consistent with the low relevance of the distance to closest colony covariate in models, as breeding auks are known to be tightly linked to their colony during the breeding season (del Hoyo et al., 2010; Wright \& Begg, 1997).

Our results are a valuable complement to previous study of auks habitat preferences in the area (Lambert et al., 2017), which demonstrated the strong link of auks to their colonies during the breeding season. Springtime non-breeding auks therefore seemed to exhibit habitat preferences close to those they exhibited during the winter season (tightly linked to shallow depths, Lambert et al., 2017).

Northern fulmars exhibited increasing densities from habitat cluster A to C. However, this preference was more gradual than in the case of auks and bottlenose dolphins, with some annual variations. If the overall preference gradient remained stable through the decade, variations occurred in the amplitude of differences in predicted density between habitats. For example, in 2010 and 2011 the northern fulmar habitat preference was clearly for habitat C, while in 2004-2006 its preference was equal for habitats C and B. If the species clearly avoided coastal waters associated with river plumes, as is consistent with the known ecology of the species during its breeding period in the area (Weimerskirch et al., 2001; Mallory, 2006; Edwards et al., 2013; Lambert et al., 2017), the southward extension of the species distribution compared to the shelf edge varied across years. This may be indicative of fulmar flexibility at the southern limit of its distribution (Brittany; Cadiou et al., 2004; del Hoyo et al., 2010).

Finally, gannets had the most pronounced annual variations in habitat preferences. This result was consistent with the known flexibility of northern gannets (Nelson, 2002). Overall, the data suggested a gradient of preference from habitat cluster A to $\mathrm{C}$, but the amplitude among these three habitats varied substantially from year to year. Despite these variations, a distribution with higher densities off southern Brittany and along the entire coastline, with occurrences along the shelf edge in some years, was a recurring pattern. 
Gannets breeding in the English Channel and the Irish Sea are known to target predictable features such as tidal fronts in the English Channel and Irish Sea, or the slope upwelling in the Celtic Sea (Pettex et al., 2010; Scales et al., 2014; Lambert et al., 2017). The consistency of such a result between studies from different colonies, different years and different methodologies (telemetry and aerial surveys) suggests a low interannual variability in habitat preference for breeding gannets in the English Channel and the Irish Sea. This is consistent with the overall preference for the productive habitat cluster A highlighted here, but not with the variability among years shown in our results.

The higher variability exhibited by gannets in the BoB during the PELGAS survey compared to the literature may be due to their reproductive status. Most sighted gannets were likely non-breeders since most of the sighted gannets were identified as immature or juvenile birds (not shown). Although there was also a sizeable proportion of adults, these were likely non-breeders, since, to our knowledge, no tagged breeding gannets from French, Irish or Welsh colonies have ever been shown to forage into the BoB. Thus, sighted adults could be either sabbatical birds or early failed breeders.

Since non-breeders are less energy-demanding and not central-place constrained, individuals may be more flexible in their foraging habitats compared to breeding gannets, explaining the higher habitat preference variability in BoB compared to habitat preferences of breeding adult gannets within the English Channel and Irish Sea (Pettex et al., 2010; Scales et al., 2014; Lambert et al., 2017). This higher interannual variability in habitat preferences for non-breeders compared to breeders would be consistent with the known flexibility of the species once breeding season is over (Nelson, 2002).

The habitat preferences of common dolphin could not be resolved as both models failed to account for the observed variations in its distribution. The small variations predicted by the models did not correspond to the observed ones, which was consistent with the non-significance of the three covariates. This result suggests that environmental variables used in the PCA were uninformative for common dolphin habitat preferences, which may be driven by other parameters than those used during this study. Another hypothesis may be that the common dolphin responds to oceanographic processes at a smaller scale than the studied scale $\left(0.25^{\circ}\right.$ cells $)$.

Habitat covariates in top predator habitat modelling are generally selected because they can be considered as proxies for distribution and habitat preferences of prey. Thus, the stability in top predator habitat preferences in this study could reflect the strength of the relationships between the distribution of the targeted prey and habitat characteristics. Bottlenose dolphins and auks exhibited a stronger stability in habitat preferences. The highest densities of their preferred prey are relatively stable and predictable, with bottlenose dolphins feeding on large hakes distributed mainly in the upper slope (Spitz et al., 2006) and auks feeding on copepods (Harding et al., 2009) which are particularly abundant in river plumes during spring phytoplankton blooms (Vandromme et al., 2014). Common dolphins and gannets, with looser habitat preferences, forage mostly on small pelagic fishes (Nelson, 2002; Meynier et al., 2008), which are widely distributed in the BoB and can exhibit important interspecific and intraspecific changes in abundance and distribution among years. Therefore, it seems that the degree of habitat predictability of the targeted prey could also partly explain the degree of decadal stability observed in habitat preferences among top predators in the BoB.

\section{Conclusion}

The purpose of this study was to explore the variations of springtime habitat preferences exhibited by five mobile top predator species within the BoB over an entire decade (2004-2013). Our results showed that predators exhibited a range of responses to springtime interannual variability of pelagic habitats, from bottlenose dolphins and auks with a narrow habitat preference particularly stable over the decade to northern gannets with wider habitat preferences varying among years. There was no relationship between the type of habitat and the stability of predator preferences, as the two species with the most stable preferences targeted opposite habitats. Bottlenose dolphins targeted the habitat associated with the shelf edge, which was highly stable across time since it is associated with a topographic structure, while auks were tightly associated with river plumes, which 
was the most spatially variable habitat identified here. A continuation of this work could include performing similar analyses during the three other seasons to explore whether the trends identified here would evolve, depending on the seasons or the population breeding status (breeding versus wintering period for seabirds).

\section{Acknowledgements}

CL was funded by the French ministry in charge of research (Ministère de l'Enseigmenent Supérieur et de la Recherche, MESR) during her PhD. We are indebted to crew members on-board the R/V Thalassa and to all observers who participated in the surveys as well as to the French Agency for Marine Protected Areas (Agence des Aires Marines Protégées, AAMP) and French Ministry of Environment (Ministère de l'Environnement, de l'Énergie et de la Mer) who funded the megafauna observers. Paul Bourriau and Martin Huret (Ifremer) are acknowledged for taking care of the CTD casts and maintaining the hydrological sensors.

\section{References}

Azzelino A, Gaspari S, Airoldi S, Nani B, 2008 "Habitat use and preferences of cetaceans along the continental slope and the adjacent pelagic waters in the western Ligurian Sea" Deep Sea Research Part I 55 296-323

Ballance L T, Pitman R L, Fiedler P C, 2006 "Oceanographic influences on seabirds and cetaceans of the eastern tropical Pacific: a review" Progress in Oceanography 69 360-390

Barry J P, Dayton P K, 1991 "Physical heterogeneity and the organisation of marine communities" in J Kolasa, S T A Pickett, eds., "Ecological Heterogeneity", (New-York: Springer-Verlag) pp. 270-320

Becker E A, Forney K A, Fiedler P C, Barlow J, Chivers S J, Edwards C A, Moore A M, Redfern J V, 2016 "Moving towards dynamic ocean management: How well do modeled ocean products predict species distributions?" Remote Sensing 8149

Buckland S T, Anderson D R, Burnham K P, Laake J L, Borchers D L, Thomas L, 2001 Introduction to Distance Sampling: Estimating Abundance of Biological Populations Édition : new ed edition (Oxford ; New York: OUP Oxford)

Cañadas A, Sagarminaga R, Garcia-Tiscar S, 2002 "Cetacean distribution related with depth and slope in the Mediterranean waters off southern Spain" Deep Sea Research Part I: Oceanographic Research Papers 49 2053-2073

URL http://www.sciencedirect.com/science/article/pii/S0967063702001231

Caballero A, Ferrer L, Rubio A, Charria G, Taylor B H, Grima N, 2014 "Monitoring of a quasi-stationary eddy in the Bay of Biscay by means of satellite, in situ and model results" Deep-Sea Research II 106 23-37

Cadiou B, coordinateurs régionaux, coordinateurs départementaux, coordinateurs espèce, 2014 "Cinquième recensement national des oiseaux marins nicheurs en france métropolitaine : bilan final 2009-2012" Technical report Rapport GISOM \& AAMP Brest

Cadiou B, Pons J, Yésou P, 2004 Oiseaux marins nicheurs de France métropolitaine : 1960-2000 (Mèze (Hérault): Biotope Editions)

Certain G, Masse J, Van Canneyt O, Petitgas P, Dorémus G, Santos M B, V. R, 2011 "Investigating the coupling between small pelagic fish and marine top predators using data collected from ecosystem-based surveys" Marine Ecology Progress Series 422 23-39

Chivers S L, 2009 Encyclopedia of marine mammals chapter Cetacean Life History (Academic Press) pp. 215220 
Cotté C, d'Ovidio F, Chaigneau A, Lévy M, Taupier-Letage I, Mate B, Guinet C, 2011 "Scale-dependent interactions of Mediterranean whales with marine dynamics" Limnology and Oceanography 56 219-232

Davoren G K, Montevecchi W A, Anderson J T, 2003 "Search strategies of a pursuit-diving marine bird and the persistence of prey patches" Ecological Monographs 73 463-481

del Hoyo J, Elliot A, Christie D, 2010 Handbook of the Birds of the World (Lynx Edicions)

Doray M, Badts V, Massé J, Duhamel E, Huret M, Dorémus G, Petitgas P, 2014 Manual of fisheries survey protocols, PELGAS surveys IFREMER

Doray M, Petitgas P, Huret M, Duhamel E, Dupuy C, Romagnan J B, Spitz J, Authier M, Sanchez F, Berger L, Dorémus G, Bourriau P, Grellier P, Massé J, 2018 "The PELGAS survey: ship-based integrated monitoring of the Bay of Biscay pelagic ecosystem" Progress in Oceanography

Edwards A W J, Quinn L R, Wakefield E D, Miller P I, Thompson P M, 2013 "Tracking northern fulmar from a Scottish nesting site to the Charlie-Gibbs Fracture Zone: Evidence of linkage between coastal breeding seabirds and Mid-Atlantic Ridge feeding sites" Deep Sea Research Part II 98 438-444

Forney K A, Becker E A, Foley D G, Barlow J, Oleson E M, 2015 "Habitat-based models of cetacean density and distribution in the central north pacific" Endangered Species Research 27 1-20

Fort J, Pettex E, Tremblay Y, Lorentsen S H, Garthe S, Votier S, Pons J B, Siorat F, Furness R W, Grecian W J, Bearhop S, Montevecchi W A, Grémillet D, 2012 "Meta-population evidence of oriented chain migration in northern gannets (Morus bassanus)" Frontiers in Ecology and the Environment 10 237-242

Gaston A J, 2004 Seabirds: a natural history (Yale University Press)

Green J, Simpson J H, Legg S, Palmer M R, 2008 "Internal waves, baroclinic energy fluxes and mixing at the european shelf edge" Continental Shelf Research 28 937-950

Guilford T, Wynn R, McMinn M, Rodríguez A, Fayet A, Maurice L, Jones A, Meier R, 2012 "Geolocators reveal migration and pre-breeding behaviour of the critically endangered Balearic Shearwater Puffinus mauretanicus" PLoS One 7 e33753

Guisan A, Zimmermann N E, 2000 "Predictive habitat distribution models in ecology" Ecological modelling 135 $147-186$

Harding A M A, Egevang C, Walkusz W, Merkel F, Blanc S, Grémillet D, 2009 "Estimating prey capture rates of a planktivorous seabird, the little auk (Alle alle), using diet, diving behaviour, and energy consumption" Polar Biology 32 785-796

Hijmans R J, Etten J v, Mattiuzzi M, Sumner M, Greenberg J A, Lamigueiro O P, Bevan A, Racine E B, Shortridge A, 2014 "raster: Geographic data analysis and modeling"

URL http://cran.r-project.org/web/packages/raster/index.html

Husson F, Josse J, Le S, Mazet J, 2016 FactoMineR: Multivariate Exploratory Data Analysis and Data Mining r package version 1.31 .5

URL https://CRAN.R-project.org/package=FactoMineR

Jahncke J, Coyle K, Zeeman S I, Kachel N, Hunt G, 2005 "Distribution of foraging shearwaters relative to inner front of SE Bering Sea" Marine Ecology Progress Series 305 219-233

Jegou A, Lazure P, 1995 "Quelques aspects de la circulation sur le plateau Atlantique" in O Cendrero, I Olaso, eds., "Actas del IV Coloquia Internacional sobre Oceanografia del Golfo de Viscaya", pp. 99-106 
Jongman R H, Ter Braak C J, Van Tongeren O F, et al., 1995 Data analysis in community and landscape ecology volume 2 (Cambridge university press Cambridge)

Koutsikopoulos C, Le Cann B, 1996 "Physical processes and hydrological structure related to the Bay of Biscay anchovy "Scientia Marina 60 9-19

Lambert C, Pettex E, Dorémus G, Laran S, Stephan E, Van Canneyt O, Ridoux V, 2017 "How does ocean seasonality drive habitat preferences of highly mobile top predators? Part II: The eastern North-Atlantic" Deep Sea Research Part II

Longhurst A R, 2007 Ecological geography of the sea 2nd edition (Academic Press)

Mallory M, 2006 "The Northern Fulmar (Fulmarus glacialis) in arctic Canada: ecology, threats, and what it tells us about marine environmental conditions" Environmental Reviews 14 187-216

Meynier L, Pusineri C, Spitz J, Santos M B, Pierce G J, Ridoux V, 2008 "Intraspecific dietary variation in the short-beaked common dolphin Delphinus delphis in the Bay of Biscay: importance of fat fish" Marine Ecology Progress Series 354277

Nelson B, 2002 The atlantic gannet (Fenix Books)

Perrin W F, Wursig B, et al., 2009 Encyclopedia of marine mammals (Academic Press)

Pettex E, Bonadonna F, Enstipp M R, Siorat F, Grémillet D, 2010 "Northern gannets anticipate the spatiotemporal occurence of their prey" The Journal of Experimental Biology 213 2365-2371

Pingree R D, Garcia-Soto C, 2014 "Plankton blooms, ocean circulation and the European slope current: Response to weather and climate in the Bay of Biscay and W English Channel (NE Atlantic)" Deep Sea Research II 106 5-22

Pingree R D, Le Cann B, 1992 "Three anticyclonic Slope Water Oceanic eDDIES (SWODDIES) in the southern Bay of Biscay in 1990" Deep Sea Research 39 1147-1175

R Core Team, 2015 R: A Language and Environment for Statistical Computing R Foundation for Statistical Computing Vienna, Austria ISBN 3-900051-07-0

URL http://www.R-project.org/

Scales K L, Miller P I, Embling C B, Ingram S N, Pirotta E, Votier S C, 2014 "Mesoscale fronts as foraging habitats: composite front mapping reveals oceanographic drivers of habitat use for a pelagic seabird" Journal of The Royal Society Interface 1120140679

Simpson J, 1997 "Physical processes in the ROFI regime" Journal of Marine Systems 12 3-15

Skov H, Thomsen F, 2008 "Resolving fine-scale spatio-temporal dynamics in the harbour porpoise Phocoena phocoena" Marine Ecology Progress Series 373 173-186

Spitz J, Rousseau Y, Ridoux V, 2006 "Diet overlap between harbour porpoise and bottlenose dolphin: An argument in favour of interference competition for food?" Estuarine, Coastal and Shelf Science 70 259-270

Tew-Kai E, Rossi V, Sudre J, Weimerskirch H, Lopez C, Hernandez-Garcia E, Marsac F, Garçon V, 2009 "Top marine predators track Lagrangian coherent structures" Proceedings of the National Academy of Sciences 106 $8245-8250$

Tilstone G, Mallor-Hoya S, Gohin F, Couto A B, Sá C, Goela P, Cristina S, Airs R, Icely J, Zühlke M, et al., 2017 "Which ocean colour algorithm for MERIS in North West European waters?" Remote Sensing of Environment 189 132-151 
Vandromme P, Nogueira E, Huret M, Lopez-Urrutia A, González-Nuevo González G, Sourisseau M, Petitgas P, 2014 "Springtime zooplankton size structure over the continental shelf of the bay of biscay" Ocean Science $10821-835$

Weimerskirch H, 2007 "Are seabirds foraging for unpredictable resources?" Deep Sea Research Part II: Topical Studies in Oceanography $\mathbf{5 4} 211-223$

Weimerskirch H, Chastel O, Cherel Y, Henden J A, Tveraa T, 2001 "Nest attendance and foraging movements of northern fulmars rearing chicks at Bjornoya Barents Sea" Polar Biology 24 83-88

Wood S N, 2011 "Fast stable restricted maximum likelihood and marginal likelihood estimation of semiparametric generalized linear models" Journal of the Royal Statistical Society: Series B (Statistical Methodology) 73 3-36

URL http://onlinelibrary.wiley.com/doi/10.1111/j.1467-9868.2010.00749.x/abstract

Wright P J, Begg G S, 1997 "A spatial comparison of common guillemots and sandeels in Scottish waters" ICES Journal of Marine Science $\mathbf{5 4} 578-592$ 
- Concurrent sampling of predators and habitat unveiled their relationships in time

- PCA on environmental variables identified 3 main habitats used by predators

- Predators exhibited various habitat preferences specificity and stability in time

- Narrower habitat preferences paired with stronger stability among years

- Wider habitat preferences paired with higher variability among years 